Preprints of the

Max Planck Institute for

Research on Collective Goods

Bonn 2010/23

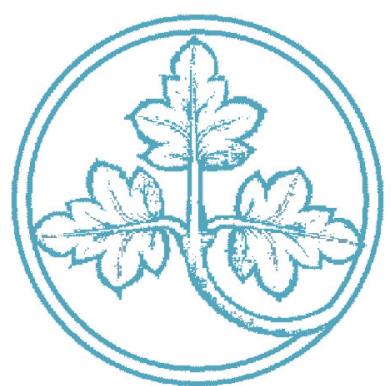

The Role of the Judiciary in the Public Decision Making Process

Giuseppe Albanese

Marco M. Sorge

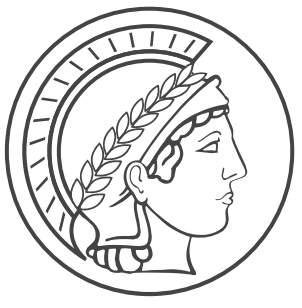




\section{The Role of the Judiciary in the Public Decision Making Process}

Giuseppe Albanese / Marco M. Sorge

May 2010 


\title{
The Role of the Judiciary in the Public Decision Making Process*
}

\author{
Giuseppe Albanese ${ }^{\dagger}$, Marco M. Sorge ${ }^{\ddagger}$
}

May, 2010

\begin{abstract}
In this paper we investigate the role of judicial control of lobbying activities in an endogenous policy framework, focusing on two dimensions of quality of the judiciary, namely efficiency and integrity. We present a multi-layer lobbying model where a self-interested group is allowed to influence a public decision maker - and possibly the judicial authority itself, which performs an anti-corruption task - with the payment of illegal contributions, and provide general conditions for the existence of a zero-contribution equilibrium. Furthermore, we study how sensitive the main findings are to different institutional arrangements as to judicial independence.
\end{abstract}

Keywords: Illegal lobbying; Endogenous policy making; Judicial control

JEL Classification: D72; D73; D78; H11; H49; H77

\footnotetext{
${ }^{*}$ We wish to thank Felix Bierbrauer, Marcello D'Amato, Valentino Dardanoni, Allan Drazen, Christoph Engel, Martin Hellwig, Giovanni Immordino, Salvatore Modica, Nicola Persico, Hamid Sabourian, Urs Schweizer and seminar/conference participants in Bonn, Pavia, Salerno and Turin for valuable comments and discussions on earlier drafts of this paper. All errors are our own. The views expressed are solely those of the authors and do not involve the responsibility of the institutions to which they belong.

${ }^{\dagger}$ Bank of Italy, Catanzaro Branch, Economic Research Unit - E-mail: giuseppe.albanese@bancaditalia.it

${ }^{\ddagger}$ BGSE, University of Bonn - E-mail: msorge@uni-bonn.de
} 


\section{Introduction}

One of the central concerns about democratic political systems is the leverage self-interested groups may claim on actual policies by means of political influence-buying and monetary contributions to policy making institutions. This phenomenon is observed to be pervasive in modern democracies and has gained a prominent position in the political economy debate.

The role of political influence was indeed noted since the middle of last century in the literature on public choice (e.g. Buchanan and Tullock, 1962; Olson, 1965; Bernholz, 1973; Hillman and Katz, 1987) and political economy of trade policy and protection (e.g. Hillman, 1982, 1989). From a purely conjectural standpoint, the seminal contributions of Stigler (1971), Grossman and Helpman $(1994,2001)$ and Dixit et al. (1997), have provided a characterization of the public decision maker as an auctioneer who may receive bids from various entities, in the form of bribes, campaign contributions, or other alluring incentives. Central to the political economy literature has thereby been the issue of investigating the equilibrium outcome of the policy making process in which pressure groups participate actively - through the provision of contributions to politicians - in order to influence political decisions.

In some political systems, notably the United States, these transfers may be perfectly legal and considered to be lobbying, whereas in other systems the same transfers would be regarded as illegal and accordingly identified as bribery. Somewhat surprisingly, while in most of the literature lobbying and bribing can be viewed as the same phenomenon ${ }^{1}$, little attention has been paid to the analysis of the influence on lobbies' ability to impinge on the decision making process of the existence of a separate government institution, namely the Judiciary, which is typically tasked with the application of the law and thus arguably concerned with political corruption.

In this respect, a major shortcoming emerging from the fairly large political economy literature on corruption and lobbying stands in that it generally neglects the active role of the judicial review, while focusing on a single public decision maker solely - typically a policy-setting body (Laffont, 2000). Judicial review has long been identified as an important component of the checks and balances against misuse of political power by the executive branch of government. In a rational choice perspective, introducing an independent judicial authority into a lobbying framework raises the question whether - and to what extent - not overseen judges will undergo pressure from special interest groups.

The present paper attempts to shed some light on this issue by presenting a multi-layer lobbying framework where policy making emerges as the outcome

\footnotetext{
${ }^{1}$ The differences between lobbying and bribing have not been extensively addressed in the theoretical literature; in the pioneering work of Grossman and Helpman (1994), lobbying takes the form of monetary transfers from lobbies to politicians, which could equally be interpreted as bribes (e.g., Coate and Morris (1999)). Harstad and Svensson (2006) attempt to draw the boundary by tackling the question why firms choose to lobby - aiming at changing existing rules or policies - or bribe - attempting to get around existing rules or policies -, and the consequences of this choice in a growth framework.
} 
of maximizing the expected net benefit of the actors affected by judicial behavior. The basic model is as follows. A political authority (bureaucrat) has discretionary power on the allocation of the tax revenue when faced with multiple projects of public good provision, which in turn benefit unequally different groups into which the population aggregates. Lobbying is endogenized in the context of a political framework where the Politician's payoff depends on total contributions and social welfare, and an organized group is allowed to submit a complete set of policy-contingent transfers, which take the form of bribes, to pursue their political aims. We aim at studying how and to what extent corruption and bribery in the political process can be curbed when vulnerable to detection from an independent authority - namely, the Judiciary - which is given the institutional role of fighting corruption embedded in the transfer of political contributions. To this end, we investigate the equilibrium properties under complete information of public decision making when accounting for both this form of multiplicity of public actors involved in the process, and the possibility that, while being independent of the political authority, the Judiciary itself may be directly pressured by the lobby ${ }^{2}$.

Existing work dealing with judicial agency has mostly focused on the corruption of law enforcers and its implications for the deterrence effectiveness of laws (e.g., Becker and Stigler, 1974); on the related issues of optimal monitoring and compensation schemes for law enforcers (e.g., Polinsky and Shavell, 2001) and of optimal regulation in the presence of corrupt contract enforcers (e.g., Immordino and Pagano, forthcoming); on the general contracting problem under judicial agency in a theoretical perspective (e.g., Bond, 2009). Nevertheless, the question whether the interdependencies between institutions and the interaction between political corruption at different government layers provides incentives to, alters or removes the lobbying activity, remains largely unanswered. In Maskin and Tirole (2004) two political entities are separately introduced in order to investigate peculiar features of a non-representative authority (the Judge) as an alternative to elective bodies (the Politician), whereas Hanssen (2004) develops further this subject examining the effects of their joint presence; in both the cases special interest groups are not present in the model and only the optimal allocation of power between accountable and nonaccountable branches of government is assessed.

More closely related to our approach are the recent works of Priks (2007) and of Mazza and van Winden (2008). The former examines how judicial dependence influences corruption at different levels of the government in a model where the central authority, low-level officials and the judiciary are potentially corrupt. Our paper differs from Priks (2008) in that we analyze the issue by means of a menu-auction model in which an organized interest group acts as principal of both the policy maker and the judiciary, whose behavior is modeled accordingly. In Mazza and van Winden (2008), an endogenous policy

\footnotetext{
${ }^{2}$ Aiming at influencing the judicial choice to their favour, i.e. toward a less "tightening" anti-corruption activity to set up. The case where interest groups face the decision of whether they should lobby the political bodies to switch policy, or rather challenge existing policy at the judicial authority is developed in Rubin, Curran and Curran (2001).
} 
model is presented in which public policies are shaped within a hierarchical government with multiple agents, and several issues involved in the strategic interaction between sequential decision making and multi-tier lobbying are addressed accordingly. In the same vein, the present work develops a simple institutional framework that aims at exploring the political interplay of two of the fundamental public institutions of modern democratic states which are assigned different tasks within the government arrangement, and the effects of their interdependencies on strategic behavior of self-interested private actors.

In our analysis, the Judiciary acts as a constraint on the executive, since its decisions bias the presence (and the magnitude) of the trading process of monetary contributions against economic policy favors or political patronage. The judicial authority is therefore regarded as an active subject concurring with the Politician in the determination of public policy. Though we acknowledge the controversial features of this definition, we follow Posner $(1994,1995)$ in that, such a public decision maker is viewed as a rational agent aiming at optimizing a payoff function where some economic variables (revenues and costs) and the political target of suing illegal activities, are linked together. The incentives of the judiciary are shaped by their internal structure as well as the institutional relationship with the political body. Indeed, similarly to Caselli and Morelli (2004) as for the latter, we measure the quality of Judiciary according to two substantive dimensions, namely efficiency and integrity. The former is defined in terms of adequate budgetary allocations, sufficient number of staff, adequate training of staff, and it is shown how it directly affects the choice of the level of the control activity to set up. The latter is defined as the degree of corruptibility by special interests, which is likely to induce distortions in the effective choice of the judicial authority. We provide a set of conditions under which illegal lobbying does not occur - i.e., it does not emerge as an equilibrium outcome of the underlying game - even in the presence of prone-to-pressure courts. In particular, we establish that general results on lobbying are not invariant with respect to multi-participant institutional environments. Our findings are in line with those of Dal Bó et al. (2006), who show that well-functioning judicial systems increase the cost of corrupt deals whereas slow and/or ineffective judicial systems raise the incentives for engaging in corrupt behavior.

Moreover, we highlight a few implications for the relationship between the behavior of executives and that of dependent judiciaries. The existence of a judicial branch of government, which is separate from and, to some degree, independent of the other branches, is a common feature among democratic states. Within the literature on separation of powers and political accountability (e.g. Alesina and Rosenthal, 1996; Persson et al., 1997), politicians are viewed as self-interested actors and legislation as a set of contracts between politicians and powerful interested parties; independence of Judiciary is thereby thought of as a mechanism for increasing the costs of rent-seeking activity and reducing the profits of pressure groups. However, a fundamental paradox highlighted in the economic and political debate on independence and political interference lies in that independence of judiciaries may in fact 
facilitate corruption in this branch because no other government entity has the authority to oversee them (e.g., Rose-Ackerman, 1978; Glaeser and Shleifer, 2002). If the Judiciary is to be an effective instrument to serve as a watch-dog over the executive, it must be both independent of it and of high integrity, that is not prone to pressure from politicians or others subjects in the private sector who benefit from a corrupt status quo. If judiciaries are independent, judges may be biased toward those who make payoffs out of a corrupt environment; if dependent, they are likely to be constrained by politicians who have power over them. The existence of an independent Judiciary can also be regarded as a key element in the successful functioning of political systems where public policies emerge from the attempts of interest groups to affect political decisions in their favour (Landes and Posner, 1975). In our simple setting, independence of the Judiciary is rather shown to be a necessary requirement for preventing the interest group and the government body from maximizing profits from the deals between them.

The remaining paper is organized as follows. Section 2 reviews some evidence and background examples of judicial corruption. The theoretical model is introduced in section 3, while section 4 carries out the equilibrium analysis. Section 5 illustrates the case of a dependent Judiciary, when endowing the political authority with the power to affect its level of efficiency or integrity. Section 6 concludes.

\section{Background}

Over the last decades, corruption issues have been given high prominence within the development and political economy debate. The pioneering work of Mauro (1995) was one of the first to show that corruption proves detrimental to investment and growth. The literature on the causes and the consequences of corruption on social welfare is by now a large chapter of public economics, as reviewed in Jain (2001) and Aidt (2003).

The starting point of our analysis is the question whether the structure of the judiciary plays a role in determining political corruption, under the assumption that judges themselves may be bribe-takers. A growing number of empirical studies exists which provide motivation to our theoretical investigation. There is no shortage of evidence about judicial corruption, though often anecdotal in character. Several instances, especially in the U.S., are indeed given in which the latter has been detected and its existence proven ex-post (e.g., McMillan and Zoido, 2004; Bond, 2009). Substantial systematic evidence points to the fact that the rule of law does not apply in many countries and that judicial decisions are in fact subject to influence (e.g. Boudreaux and Pritchard, 1994; Collins, 2008). Some legal histories seem to suggest that judicial agency has played an important role historically (e.g., Hoeflich, 1984), while both anecdotal and survey evidence claim that it still shapes a pervasive phenomenon in developing countries nowadays (e.g., Hellman et al., 2000). 
A few strands of econometric research have demonstrated the beneficial effects of judicial independence for economic growth and social welfare, developing numerous indicators and providing evidence that countries with strong independence of judicial institutions enjoy higher economic performance and political freedom. The seminal contribution of Feld and Voigt (2003) introduces a twofold notion of judicial independence - de jure independence, as described in the constitutional establishment of the supreme court, and de facto independence, that is judicial independence as it is actually implemented in practice; exploiting a cross-sectional sample they present evidence that only de facto judicial independence is conducive to growth. In a related work, Feld and Voigt (2004) also control for interaction effects conjecturing that other constitutional arrangements such as the degree of checks and balances (Persson and Tabellini, 2003) might - jointly with judicial independence - also have an impact on economic growth. La Porta et al. (2004) use an international database assembling measures of judicial checks and balances for seventy-one countries to show that effective judicial independence and constitutional review account for greater economic freedom.

In this paper, illegal lobbying is studied within a multi-institutional government organization involving different types of actors and separation of powers. A leading concern of our framework pertains to the relationship between judicial independence and political corruption. We start from the simple hypothesis that, being the likelihood of politicians being bribed strongly dependent on the expected utility of engaging themselves in corrupt behavior, a higher likelihood of the latter being detected and prosecuted should be correlated with lower levels of political corruption.

Closely related to our work are the empirical contributions suggesting that judicial dependence plays an important role in explaining high levels of corruption. Ades and Di Tella (1997) and La Porta et al. (2004) show that political influence over judicial institutions typically increases corruption. More recently, Aaken et al. (2008) takes on an estimation strategy - based on the construction of two ad hoc indicators of independence - in order to test the hypothesis whether government power over prosecutors may raise government members' incentives to misuse such power in order to prevent the prosecution of illegal activities or crimes - like corruption - committed by themselves. The cross country evidence provided in the paper shows that factual independence of prosecutors is robustly significant for explaining variation in political corruption.

\section{The model}

We consider an economy with a population of $N$ individuals divided into two groups indexed by $k$, of size $n_{1}$ and $n_{2}$ respectively, with $\sum_{k=1}^{2} n_{k}=N$. Utility (welfare) is derived from disposable income, which is assumed to be exogenous, and the consumption of pure group-specific public goods. Under 
homogeneous preferences within each group we have:

$$
U_{k}=n_{k} u_{k}
$$

with the individual utility function characterized as:

$$
u_{k}=(1-t) y_{k}+G_{k}\left(q_{k} B\right)
$$

where:

- $y_{k}$ denotes gross income for individuals of group $k$;

- $t$ is the exogenously given tax rate on gross income;

- $G_{k}(\cdot)$ denotes utility derived from the public good $q_{k} B$ specific to group $k$;

- $q_{k} \geq 0$ is the share of total tax revenue $\left(B=t \sum_{k} n_{k} y_{k}\right)$ dedicated to finance the project that benefits either group, with $\sum_{k} q_{k}=1$;

- $G_{k}$ is a twice-differentiable function satisfying $G_{k}^{\prime}(\cdot)>0$ and $G_{k}^{\prime \prime}(\cdot)<0$ for $k=1,2$.

The effective redistribution scheme results from the interplay of two government institutions. While public policies are univocally determined by the decisions of a Politician $(P)$, their determination is influenced by the behavior of a separate institution, the Judiciary $(J)$, which is given the role of tracing illegal lobbying at the Politician's level. In a setting á la Grossman and Helpman (2001), an organized interest group $k$ may indeed decide to make its political contribution contingent on the selected policy by formulating a transfer schedule $T_{k}\left(q_{k}\right)$ which maps any feasible value for the shares $q_{k} \in[0,1]$ into a non-negative contribution to $P^{3}$. In our simple economy, contributions are assumed to be illegal whichever form or submission channel they might take (outright bribes). As $P$ will choose the policy vector $\left(\hat{q}_{1}, \hat{q}_{2}\right)$ which maximizes its own objective, the joint (net) welfare of the members of the lobbying group $k$ is given as:

$$
V_{k}=U_{k}\left(\hat{q}_{k}\right)-T_{k}\left(\hat{q}_{k}\right)
$$

We model a reduced form for the Politician's objective function, assuming that fixed weights are exogenously assigned to the welfare levels of the two different groups in the economy ${ }^{4}$. When choosing the tax revenue shares $q_{k}$ to be allocated for the production of the public goods, the policy-setting authority $P$ is thereby concerned with the public's well-being and with the receipts it gets from the groups of interest. We explicitly allow for uncertainty in the payment of the contributions - which mirrors the degree to which the policy

\footnotetext{
${ }^{3}$ We require the contribution function be differentiable for strictly positive contributions.

${ }^{4}$ In our model, $\theta_{k}$ reflects political relevance and may represent population weights (e.g., when the Politician takes care of social welfare) or electoral weights (when the Politician is concerned with reelection prospects).
} 
maker is actually captured by interest groups' claims - as linked to the presence of the control activity undertaken by the Judiciary. This feature is modeled by letting $P$ benefit from the effective transfers only with (known) probability $f \in[0,1]$, so that a risk-neutral Politican chooses $q \in[0,1]$ to maximize:

$$
V_{P}=f \sum_{k=1}^{2} T_{k}\left(q_{k}\right)+l \sum_{k=1}^{2} \theta_{k} V_{k}\left(q_{k}\right)
$$

where:

- $\sum_{k} \theta_{k} V_{k}(\cdot)$ is the social welfare aggregation with weights $\theta_{k}>0$ for $k=1,2$, and $\sum_{k} \theta_{k}=1$;

- $l>0$ denotes the (exogenous) degree of preference of $P$ for (weighted) social welfare relative to contributions.

Groups may differ in their ability to capture institutions and outbid rival seekers of favorable policies. Given our concern in exploring the endogenous interaction between multi-target lobbying and judicial control under different hypotheses as to the integrity and independence of the Judiciary, for simplicity the asymmetric case is considered where group 1 only is modeled as a bribe provider $^{5}$. To ease notation burden, we set $q_{1}=q$ (and $q_{2}=1-q$ accordingly), so that $T(q)$ and $\widehat{T} \equiv T(\hat{q})$ will denote the contribution function with which the lobby confronts the Politician and the effective transfer eventually paid by the lobby against the chosen policy $\hat{q}$, respectively. The payoff function of $P$ reduces then to:

$$
V_{P}=f T(q)+l \sum_{k=1}^{2} \theta_{k} V_{k}\left(q_{k}\right)
$$

The judicial authority is in charge of an anti-corruption office incidental to the effective transfer of the contributions $\widehat{T}$. In particular, we assume the existence of one-to-one correspondences ${ }^{6}$ between the control activity carried out by $J$ and both the probability $1-f$ with which it traces the payment $\widehat{T}$ and a cost, determined by an uni-variate function $S$, in terms of effort to be exerted or resource allocation for the anti-corruption task to take place ${ }^{7}$. We thereby consider $f$ as the choice variable for $J$ and denote with $S(f)$ the cost associated with any level of control activity:

$$
S(f)=\alpha^{-1}(1-f), \quad \alpha>0
$$

\footnotetext{
${ }^{5}$ We let then group 2 collect the rest of the population, so that the public good 1 would represent a specific good in which group 1 is interested, whereas the public good 2 would denote a generic basket of other goods.

${ }^{6}$ That is, of a pair of bijections, whose composition is bijective as well.

${ }^{7}$ It turns indeed difficult to believe that the probability $f$ is observable by economic agents. Therefore, we think of $1-f$ as a proxy of the level of effort or resource allocation needed for the detection of outright bribes at the Politician's level, measured by the function $S(f)$. Observing the latter is of course equivalent to observing the shadow price of political lobbying $f$.
} 
so that positively identifying any illegal contribution submitted to $P$ is costly but bounded from above $(S(0)=1 / \alpha)$, while not identifying it involves no cost at all $(S(1)=0)^{8}$. The positive parameter $\alpha$ is assumed to be a measure of efficiency for $J$ 's control activity; it summarizes the influence of adequate budgetary allocations, sufficient number of staff, adequate training of staff on the judicial work. Although efficiency is only one aspect of the quality of a Judiciary, it nonetheless is measurable, unlike some of the other essential features (Dakolias, 1999).

As to the objective of $J$, in line with the expression for $V_{P}$ we assume that the former reflects the burden imposed by lobbying activities at the Politician's level - in terms of costs of anti-corruption task and the discrepancy (measured by the ex-post transfer $T(\hat{q})$ ) between the allocation resulting in the absence of any dealings with the interest group and the lobby-induced one - as well as the opportunity of benefiting (constantly at the margin) from direct transfers from the interest group:

$$
V_{J}(f)=(1-\lambda) C(f)+\lambda[-S(f)-T(\hat{q})], \quad \lambda \in[0,1]
$$

where $\lambda$ - the weighting factor placed on organization and social costs of corruption versus monetary transfers - is interpreted as $J$ 's level of integrity, and $C(f)$ denotes the contribution schedule tendered by the lobby. For the sake of convenience, the previous expression - taken to be maximized over $f \in[0,1]$ is written in the following form:

$$
V_{J}(f)=(1+\sigma)^{-1}[(-S(f)+\sigma C(f))-T(\hat{q})], \quad \sigma \geq 0
$$

where the scalar $\sigma=\lambda^{-1}(1-\lambda)$ can be regarded as the degree of corruptibility held by the judicial authority.

We assume that the objectives (3) and (5) are common knowledge to $P, J$ and the organized interest group. In this context lobbying proves observable but not verifiable by the Judiciary unless contributions are detected through its control activity. Also, we make a strong assumption in that, once identified, the contribution $\widehat{T}$ is confiscated but can neither contribute to financing public goods provision nor be of any utility for $J$.

\section{Equilibrium analysis}

\subsection{One-layer lobbying}

We first investigate the case where only the political authority may be contributed by the lobby, that is $\sigma=0$ and (5) turns into:

$$
V_{J}(f)=-\left(\alpha^{-1}(1-f)+T(\hat{q})\right), \quad \alpha>0
$$

so that $J$ 's objective is given by the sum (with negative sign) of the cost of the anti-corruption task as expressed by (4) and the ex-post transfer to the Politician. The timing of the model is as follows:

\footnotetext{
${ }^{8}$ There is no sunk cost associated with the described control activity.
} 
(i) $J$ selects the level of control activity, determining $f$;

(ii) the lobbying group 1 formulates the contribution schedule $T(q)$;

(iii) $P$ observes $T(q)$ and sets the policy $\hat{q}$, the lobby pays $T(\hat{q})$;

(iv) if not traced, the contribution is received by $P$.

We derive the subgame-perfect equilibrium (SPE) of the model through backward induction. A few preliminary comments are worth making. First, the analysis is restricted to the equilibrium profile insofar as the results obtained are invariant with respect to the form of the contribution schedule off-the equilibrium. Also, the assumption that the bargaining power is fully allocated to the lobby does not impose any restrictions on the equilibrium outcome of the model. In our setting, the first-mover advantage allows indeed the lobby to fully extract the surplus. Yet, we may as well let the Politician and the lobby share equally the gain or also allow the Politician to take it in full ${ }^{9}$. Crucially, $f$ is not taken to be a function of the size of the contribution $T$, which therefore still enters additively the objective of the policy-setting authority; it follows that under Nash bargaining - or any different bargaining structure with full information whose solution is jointly (Pareto) efficient for both the contracting sides - the equilibrium policy proves independent of the negotiation process (Grossman and Helpman, 2001; Peters, 2003).

Implicitly it is assumed that, even if the Politician and the lobby choose not to stipulate any contract, the relationship between the two is ongoing, so that policies and schedules are adhered to in order to preserve the possibility of future cooperation. Similarly, the Judiciary commits to carry out the costly level of control as chosen in stage (i).

As to the stage of policy making, where $f^{*}$ is predetermined, using (2) and (3), the objective function for $P$ becomes:

$$
V_{P}=f^{*} T(q)+l \sum_{k=1}^{2} \theta_{k}\left(U_{k}-T_{k}\right)=\left(f^{*}-l \theta_{1}\right) T(q)+l \sum_{k=1}^{2} \theta_{k} U_{k}\left(q_{k}\right)
$$

From this formulation, it is straightforward to note that $P$ will give in to the lobbying group (accepting $\widehat{T}$ ) only if the probability of obtaining the contribution exceeds a given threshold (i.e., $\left.l \theta_{1}\right)$. Indeed, a sufficient condition for the absence of lobbying can be stated in terms of the parameter restriction $l \theta_{1} \geq 1$; conversely, whenever the latter fails to obtain, the group of interest will be able to bear down on the public agent $P$ by means of political (monetary) contributions only if the level of impunity enjoyed by the lobbying activity is larger than the given threshold. More precisely, we have the following result:

Proposition 1. In the SPE of the model:

i) If $l \theta_{1} \geq 1$, no lobbying emerges and $P$ chooses $\hat{q}^{*}=\operatorname{argmax}_{q} l \sum_{k} \theta_{k} U_{k}\left(q_{k}\right)$;

\footnotetext{
${ }^{9}$ All these remarks also apply for the lobbying game between the interest group and the Judiciary
} 
ii) If $l \theta_{1}<1$ and $f^{*} \leq l \theta_{1}$, no lobbying emerges and $P$ chooses $\hat{q}^{*}$;

iii) Iff $f^{*}>l \theta_{1}$, the organized group lobbies $P$ and obtains $\hat{q}^{L}>\hat{q}^{*}$.

In the first two cases, the lobby offers $T=0$ and no interaction with the public agent $P$ takes place. The equilibrium policy for any $f^{*} \leq l \theta_{1}$ is implicitly determined by the first-order condition $^{10}$ :

$$
\sum_{k=1}^{2} \theta_{k} U_{k}^{\prime}\left(\hat{q}^{*}\right)=\sum_{k=1}^{2} \theta_{k} n_{k} G_{k}^{\prime}\left(\hat{q}^{*}\right)=0
$$

Although the two possibilities bring about the same results in terms of optimal choice by the Politician, they have no common source. In the first case, lobbying is not even feasible, because of the level of welfare-interest of the Politician, that makes too costly for the interest group to pay contributions. We define this as the First Best (FB) equilibrium. In the second case, while otherwise feasible, lobbying does not emerge because of the level of judicial control. We denote this with the term Full Deterrence (FD) equilibrium. In the former case therefore, the presence of Judiciary is non influential, whereas in the latter it proves fundamental.

In the third case, a subgame-perfect equilibrium entails at the lower node a policy-contribution pair $\left\{\hat{q}^{L}, T^{L}\right\}$ such that $\hat{q}^{L}$ jointly maximizes the objective function of $P$ and the lobbying group, the latter acting as a principal ${ }^{11}$. The equilibrium is then defined by:

$$
\left(f^{*}-l \theta_{1}\right) T^{\prime}\left(\hat{q}^{L}\right)+l \sum_{k=1}^{2} \theta_{k} U_{k}^{\prime}\left(\hat{q}^{L}\right)=0
$$

subject to:

$$
U_{1}^{\prime}\left(\hat{q}^{L}\right)-T^{\prime}\left(\hat{q}^{L}\right)=0
$$

which gives the first-order condition:

$$
f^{*} U_{1}^{\prime}\left(\hat{q}^{L}\right)+l \theta_{2} U_{2}^{\prime}\left(\hat{q}^{L}\right)=0
$$

It is straightforward to note that the main effect of the lobbying activity relative to the no lobbying case is to have the weight $P$ grants its marginal utility increased (since $f^{*}>l \theta_{1}$ ). Given the strict concavity of the utility function, the budget share turns improved $\left(\hat{q}^{L}>\hat{q}^{*}\right)$ so that $U_{1}\left(\hat{q}^{L}\right)>U_{1}\left(\hat{q}^{*}\right)$ and $U_{2}\left(1-\hat{q}^{L}\right)<U_{2}\left(1-\hat{q}^{*}\right)$. Clearly, for the contribution $T^{L} \equiv T\left(\hat{q}^{L}\right)$ to be an

\footnotetext{
${ }^{10}$ This requirement fully characterizes the optimal choice of $P$, since $U_{k}$ is concave in $q_{1} \equiv q$ for $k=1,2$.

${ }^{11}$ The equilibrium allocation must be jointly efficient for the organized group and the policy-setting authority, that is $\hat{q}^{L}=\operatorname{argmax}_{q}\left\{V_{1}(q)\right\}$ s.t. $\quad V_{P}(q, T(q)) \geq$ $V_{P}\left(\hat{q}^{*}\right) \equiv \max _{q} l \sum_{k} \theta_{k} U_{k}\left(q_{k}\right)$. Computing the contribution $T^{L}$ required by full surplus extraction, the efficient policy maximizes the payoff of the lobby, that is $\hat{q}^{L}=$ $\operatorname{argmax}_{q}\left\{f^{*} U_{1}(q)+l \theta_{2} U_{2}(1-q)\right\}$, as required by equation (7). Again, the second-order condition for $\hat{q}^{L}$ is guaranteed by concavity.
} 
equilibrium it cannot be lowered further without inducing the public decision maker to change its optimal choice. From:

$$
V_{P}\left(\hat{q}^{*}, 0\right)=l \sum_{k=1}^{2} \theta_{k} U_{k}\left(\hat{q}^{*}\right)
$$

and:

$$
V_{P}\left(\hat{q}^{L}, T^{L}\right)=\left(f^{*}-l \theta_{1}\right) T^{L}+l \sum_{k=1}^{2} \theta_{k} U_{k}\left(\hat{q}^{L}\right)
$$

it follows:

$$
T^{L}=\frac{l}{f^{*}-l \theta_{1}}\left\{\theta_{1}\left[U_{1}\left(\hat{q}^{*}\right)-U_{1}\left(\hat{q}^{L}\right)\right]+\theta_{2}\left[U_{2}\left(\hat{q}^{*}\right)-U_{2}\left(\hat{q}^{L}\right)\right]\right\}
$$

It is evident that $\frac{\partial T^{L}}{\partial q^{L}}=-\frac{1}{f^{*}-l \theta_{1}}\left[l \theta_{1} \frac{\partial U_{1}}{\partial q^{L}}+l \theta_{2} \frac{\partial U_{2}}{\partial q^{L}}\right]>0$ from (7), so that from $\hat{q}^{L}>\hat{q}^{*}$ it follows $T^{L}>0$. This proves sufficiency for the last claim of Proposition 1. It is worth mentioning that the participation constraint of the lobbying group is not binding in equilibrium ${ }^{12}$, this meaning that, relative to the no lobbying scenario, group 1 experiences an increase in its payoff and group 2 faces a decreased payoff, with $P$ not being worse off in the political equilibrium by accepting the incentive contract.

Now we turn to the analysis of the first stage of the game. In order to perform its anti-corruption task, the judicial authority chooses the level of control activity to be set up by minimizing $[S(f)+\widehat{T}]$ over $f$, the probability with which the contribution $\widehat{T}$ is effectively delivered to the public agent $P$. While the operative cost $S(f)$, in terms of effort or resource allocation required by any control actions, suggests that weakening the anti-corruption activity - by letting the level of impunity enjoyed by the lobbying group be high involves, at any efficiency level $\alpha$, a benefit for $J$, the effect of $f$ on $\widehat{T}$ - which is key to investigating how the Judiciary attempts to influence the existence and the magnitude of illegal contributions - is ambiguous.

Two different scenarios can thereby emerge. Under $l \theta_{1} \geq 1$ Proposition 1 ensures that lobbying never occurs; with $T=0$, every non-zero level for the control activity of the Judiciary is of no use, and the optimal choice does result in $f=1^{13}$. Conversely, if $l \theta_{1}<1$ - a restriction which would be otherwise sufficient for lobbying to occur - the model allows us to derive a pair of functions $(\hat{q}(f), \widehat{T}(f))$ which map from any value for $f$ in $[0,1]$ to the corresponding optimal choice of $P$ and the transfer effectively submitted by the lobbying group, respectively, under which $\widehat{T}\left(l \theta_{1}\right)=0$ and $\widehat{T}(f)>0$ for all $f$ larger than this threshold. The response of $\widehat{T}(f)$ to a marginal variation in $f$ is:

$$
\frac{\partial \widehat{T}(f)}{\partial f}=-\frac{l}{\left(f-l \theta_{1}\right)^{2}} \sum_{k=1}^{2} \theta_{k}\left[U_{k}\left(\hat{q}^{*}\right)-U_{k}\left(\hat{q}^{L}\right)\right]-\frac{l}{f-l \theta_{1}} \sum_{k=1}^{2} \theta_{k} \frac{\partial U_{k}}{\partial f}
$$

\footnotetext{
${ }^{12}$ That is, $U_{1}\left(\hat{q}^{L}\right)-T\left(\hat{q}^{L}\right)>U_{1}\left(\hat{q}^{*}\right)$. This shows that the interest group has an incentive to lobby $P$ for any $f>l \theta_{1}$ chosen at the upper node.

${ }^{13}$ This justifies our definition of First Best outcome, since no costly action by the Judiciary is necessary to achieve the maximum welfare condition.
} 
This relation captures the equilibrium trade-off induced by an higher level of impunity $f$. While the first term in the right-hand side has negative sign - an higher $f$ grants the lobbying group a strong bargaining power, allowing it to submit the lowest contribution satisfying the participation constraint of $P_{-}$, the second term turns positive as it reflects the equilibrium responses of the system due to the lobbying activity of the organized group. From $\frac{\partial U_{1}}{\partial f} \equiv$ $\frac{\partial U_{1}}{\partial q^{L}} \frac{\partial q^{L}}{\partial f}>0$ and $\frac{\partial U_{2}}{\partial f} \equiv \frac{\partial U_{2}}{\partial q^{L}} \frac{\partial q^{L}}{\partial f}<0$, and given condition (7), the higher the value of $f$ the larger the incentive distortion induced in the optimal behavior of $P$ as a welfare-maximizer and accordingly the higher the compensation to credit to the public agent in terms of the contribution $\widehat{T}(f)$.

Given differentiability and compactness assumptions, a solution to the optimization problem of $J$ does exist. The following Lemma claims that there always exists a lower bound for the efficiency parameter $\alpha$ above which the judicial authority will be able to fully deter political lobbying:

Lemma 1. Let $l \theta_{1}<1$. Then there always exists a finite threshold $\bar{\alpha}$ such that $J$ prefers $f^{*}=l \theta_{1}$ to any $f \in[0,1]$ if and only if $\alpha \geq \bar{\alpha}$.

Proof. - See Appendix A.

Therefore, Proposition 1 and Lemma 1 jointly show that in two cases only the same equilibrium outcome ${ }^{14}$ can be achieved. The first possibility trivially obtains when lobbying is unfeasible, provided the Politician is sufficiently welfare interested - that is, when $l \theta_{1} \geq 1$. Otherwise, provided that requirements of Lemma 1 are met, there would be no gain for group 1 in engaging into political lobbying ${ }^{15}$.

Along the same chain of reasoning (assuming $l \theta_{1}<1$ ), $f=1$ is chosen if and only if $\alpha$ is lower than a given (finite) threshold $\alpha^{\circ}>\bar{\alpha}$, since in that case every level of control is too costly for $J$. As a consequence, no deterrence obtains in the political equilibrium only when $J$ proves highly inefficient; with intermediate values for $\alpha, J$ could indeed prefer a different $f \in\left(l \theta_{1}, 1\right)$, which results in a political equilibrium with partial lobbying deterrence.

\subsection{Two-layer lobbying}

In this section, we investigate the possibility that, while being independent of the political authority, $J$ itself may be bribed by the pressure group. With some algebra, it is possible to rewrite the first term in the right-hand side of equation (9) and use (7) to obtain:

$$
\frac{\partial U_{1}}{\partial f}-\frac{\partial \widehat{T}}{\partial f}=\frac{1}{\left(f-l \theta_{1}\right)^{2}}\left\{l \theta_{1}\left[U_{1}\left(\hat{q}^{*}\right)-U_{1}\left(\hat{q}^{L}\right)\right]+l \theta_{2}\left[U_{2}\left(\hat{q}^{*}\right)-U_{2}\left(\hat{q}^{L}\right)\right]\right\}
$$

\footnotetext{
${ }^{14}$ More precisely, the same result in terms of absence of lobbying - and hence of the optimal shares $\hat{q}_{k}^{*}$ - in the political equilibrium. As shown, the optimal choice of the Judiciary proves different under the two circumstances. See also next note.

${ }^{15}$ This leads to our definition of Full Deterrence equilibrium, given the cost borne by the public agent $J$ for achieving the optimal condition as expressed in Proposition 1.
} 
which proves positive as the payoff of the lobby group is a monotone function of the level of impunity $f$. This clearly raises the question whether - and under which conditions - it may turn optimal for the special interest group to lobby the judicial authority at the first stage of the game, by submitting contributions contingent on $J$ 's decision. When faced with multiple access points to the decision making, the analysis of the allocation of influence activities calls for an evaluation of the lobby's strategic behavior as to how best to exploit resources to impinge on the process and which choices it should attempt to affect, while accounting for the possibility that lobbying at one layer may not suffice to fully control reactions by the other.

The objective for the judicial authority is now given by equation (5), which we repeat below, under the restriction $\sigma>0$ :

$$
V_{J}(f)=(1+\sigma)^{-1}\left[\left(-\alpha^{-1}(1-f)+\sigma C(f)\right)-T(\hat{q})\right], \quad \alpha, \sigma>0
$$

whereas $P$ 's objective is given as:

$$
V_{P}=\hat{f} T(q)+l \sum_{k=1}^{2} \theta_{k}\left\{U_{k}\left(q_{k}\right)-T_{k}\left(q_{k}\right)-C_{k}(\hat{f})\right\}
$$

where, according to our assumptions, only $T_{1} \equiv T$ and $C_{1} \equiv C$ can take on non-zero values. The sequence of events therefore includes a preliminary stage where interest group 1 decides whether to lobby $J$ with a contribution schedule $C(f)$, and $J$ selects the level of control activity to set up and therefore the value $\hat{f}$ maximizing (10), obtaining the matching monetary reward $C(\hat{f}) \geq 0$. Then, the same group 1 decides whether to lobby $P$ by submitting a policycontingent schedule $T(q)$, and finally the latter chooses a budget allocation $\{\hat{q}, 1-\hat{q}\}$ maximizing (11) and exchanged for $T(\hat{q}) \geq 0$.

At the lowest node, $P$ cannot influence the choice made by $J$ on the level of impunity to be granted to the lobbying activity, independently of the ability of the group of interest to bribe the judicial authority. It follows that $\hat{f}$ and $C(\hat{f})$ are predetermined at this node of decision making and the expression for the optimal $T^{L}(\hat{f})$ is obtained as in the previous section.

As the upper node, the optimal choice for $f$ is jointly efficient for $J$ and the lobby ${ }^{16}$ :

$$
\hat{f}^{L}=\operatorname{argmax}_{f \in[0,1]}\{-S(f)-\widehat{T}(f)+\sigma C(f)\} \quad \text { s.t. } \quad \frac{\partial U_{1}}{\partial f}-\frac{\partial \widehat{T}}{\partial f}-C^{\prime}(f)=0
$$

where:

$$
C^{\prime}(f)=\frac{1}{\left(f-l \theta_{1}\right)^{2}}\left\{l \theta_{1}\left[U_{1}\left(\hat{q}^{*}\right)-U_{1}\left(\hat{q}^{L}\right)\right]+l \theta_{2}\left[U_{2}\left(\hat{q}^{*}\right)-U_{2}\left(\hat{q}^{L}\right)\right]\right\}
$$

is always positive for $f \in\left(l \theta_{1}, 1\right]$ as the group of interest 1 is willing to lobby the public agent $J$ for this to grant an higher level of impunity to the lobbying

\footnotetext{
${ }^{16}$ Note that lobbying the Judiciary at this stage of the game is feasible insofar as $\lambda<1$ or $\sigma>0$.
} 
activity intended to affect $P$ 's choice over public spending allocation. It follows then $\hat{f}^{L} \geq \hat{f}^{*}$, with $\hat{f}^{*}$ denoting the optimal choice resulting under no lobbying at $J$ 's level.

We can thereby compute $C\left(\hat{f}^{L}\right)$ as the contribution which leaves $J$ indifferent between choosing $\hat{f}^{L}$ and keeping the level of control corresponding to $\hat{f}^{*}$ :

$$
S\left(\hat{f}^{*}\right)+\widehat{T}\left(\hat{f}^{*}\right)=S\left(\hat{f}^{L}\right)+\widehat{T}\left(\hat{f}^{L}\right)-\sigma C\left(\hat{f}^{L}\right)
$$

or:

$$
C\left(\hat{f}^{L}\right)=\frac{1}{\sigma}\left[-\frac{\left(\hat{f}^{L}-\hat{f}^{*}\right)}{\alpha}+\widehat{T}\left(\hat{f}^{L}\right)-\widehat{T}\left(\hat{f}^{*}\right)\right]
$$

As an equilibrium requirement, the participation constraint of the lobbying group must be satisfied, so we need to impose:

$$
U\left(\hat{q}\left(\hat{f}^{L}\right)\right)-\widehat{T}\left(\hat{f}^{L}\right)-C\left(\hat{f}^{L}\right) \geq U\left(\hat{q}\left(\hat{f}^{*}\right)\right)-\widehat{T}\left(\hat{f}^{*}\right)
$$

Again, we look for the conditions under which the economy is able to reach an equilibrium where no illegal transfer to both the public agents occurs. Accordingly, we shall assume hereafter that $\alpha \geq \bar{\alpha}$ is always the case ${ }^{17}$, so that from Lemma 1 it follows $\hat{f}^{*}=l \theta_{1}$. Corrupting the judicial authority via a positive contribution would instead yield $\hat{f}^{L}$ : since $\bar{\alpha}$ has been proven to be the minimal level of efficiency such that $l \theta_{1} \equiv \operatorname{argmax}\{-S-T(\hat{q})\}$ in $[0,1]$, and since $C(f)>0$ for $f>l \theta_{1}$, we have $\hat{f}^{L}>l \theta_{1}$.

The contribution to be paid to $J$ amounts then to:

$$
C\left(\hat{f}^{L}\right)=\frac{1}{\sigma}\left[-\frac{\left(\hat{f}^{L}-l \theta_{1}\right)}{\alpha}+\widehat{T}\left(\hat{f}^{L}\right)\right]
$$

with $C\left(\hat{f}^{L}\right)$ fulfilling equation (13), which is equivalent to requiring:

$$
\frac{1}{\sigma}\left[-\frac{\left(\hat{f}^{L}-l \theta_{1}\right)}{\alpha}+\widehat{T}\left(\hat{f}^{L}\right)\right] \leq U\left(\hat{q}\left(\hat{f}^{L}\right)\right)-U\left(\hat{q}^{*}\right)-\widehat{T}\left(\hat{f}^{L}\right)
$$

Since this holds for any $\alpha \geq \bar{\alpha}$, we state the following:

Lemma 2. Let $l \theta_{1}<1$. Then there always exists a non-zero threshold $\bar{\sigma}$ such that, for a sufficiently high $\alpha, J$ selects $\hat{f}^{*}=l \theta_{1}$ if and only if $\sigma<\bar{\sigma}$.

Proof. - See Appendix B.

Lemma 2 ensures that, for sufficiently low corruptibility levels, the problem is analogous to that dealt with in section 4.1. It identifies a partition of the parameter space $\sigma \in[0, \infty]$ in accordance with the threshold $\bar{\sigma}$. A zero-contribution equilibrium therefore obtains in the multi-target case under identifiable parameter restrictions. While for high corruptibility levels no equilibrium without illegal transfers is achievable, even in the presence of maximum

\footnotetext{
${ }^{17}$ We have already shown that a contributions free equilibrium is not possible if $\alpha<\bar{\alpha}$ even when the Judiciary is not corruptible.
} 


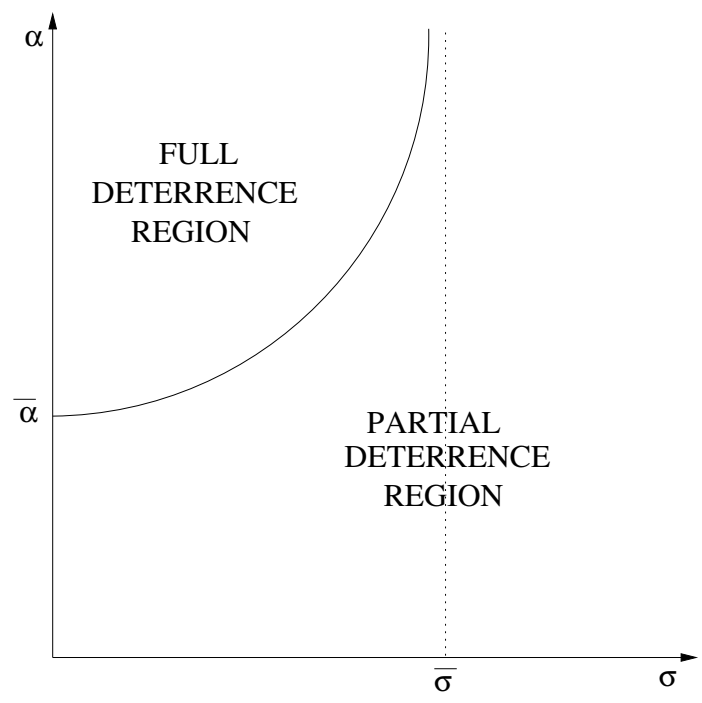

Fig. 1: Feasibility of the Full Deterrence equilibrium.

efficiency, for $\sigma<\bar{\sigma}$ a zero-contribution equilibrium is still feasible, conditional on a sufficiently high level of efficiency.

We now characterize the problem in terms of both the efficiency and the integrity of the Judiciary according to the following:

Corollary 1. Let $l \theta_{1}<1$. Provided that $\sigma<\bar{\sigma}$, there always exists a finite $\overline{\bar{\alpha}}$ such that $J$ prefers $f^{*}=l \theta_{1}$ to any $f \in[0,1]$ if and only if $\alpha \geq \overline{\bar{\alpha}}$. In particular, we have $\overline{\bar{\alpha}}=\alpha(\sigma)$ with $d \overline{\bar{\alpha}} / d \sigma>0$

Proof. - See Appendix C.

The existence of a monotone mapping between degrees of $J$ 's corruptibility and the minimal level of efficiency needed for full deterrence to occur identifies a non-empty subset $A \subset \Re_{++} \times \Re_{+}$in the parameter space such that absence of lobbying in the political equilibrium obtains if and only if the pair $(\alpha, \sigma) \in A$ (Figure 1). In other words, provided requirements of Lemma 2 and Corollary 1 are met, a level of enforcement that fully deters political lobbying may result even in the presence of a prone-to-pressure Judiciary. The following claim complements this insight:

Corollary 2. Let $l \theta_{1}<1$. Then $f=1$ obtains if and only if $\alpha<\underline{\alpha}(\sigma)$ with $\underline{\alpha}(\sigma)>0$ and $d \underline{\alpha} / d \sigma>0$

Proof. - See Appendix D.

\section{Lobbying under judicial dependence}

This last section develops a slightly more sophisticated analysis in terms of presence of a dependent or independent Judiciary. Herein, the aim of inquiry is not the reasons of existence of the judicial authority as an institution 
independent of the political arm of government but rather the discretion in choice enjoyed by and the nature of the constraints imposed on the Judiciary, as expressed by the mechanisms underpinning the independence of the judicial branch from political interference. Rather than specifying how $P$ and $J$ are appointed, we thereby formalize this feature by postulating that Nature always selects the level of $l$ (i.e. the level of welfare interest of the Politician) while it chooses the level of $\sigma$ (i.e. the degree of corruptibility of the Judiciary) only in the case of independence of $J$. Judicial dependence is then modeled as the power acknowledged to the Politician to select the parameter $\sigma^{18}$.

The case of an independent Judiciary immune from political interference corresponds exactly to our previous section. In that situation, $l$ and $\sigma$ are independently given, so that the regions of presence or absence of illegal contributions are obtained under the requirements of Proposition 1 and Lemma 2. This scenario is depicted in Figure 2, which shows three possible regions according to the thresholds $\bar{\sigma}$ and $\bar{l}=1 / \theta_{1}$. Given Proposition 1 , if $l \geq \bar{l}$ we always achieve the First Best solution thanks to the welfare interest of the Politician. If $l<\bar{l}$ but $\sigma<\bar{\sigma}$, Lemma 2 applies so that we achieve the Full Deterrence solution conditional on the efficiency of the Judiciary being sufficiently high. Only when the welfare interest of $P$ and the integrity of $J$ are both low (that is, $l<\bar{l}$ and $\sigma>\bar{\sigma}$ ), $\hat{q}^{*}$ is unfeasible.

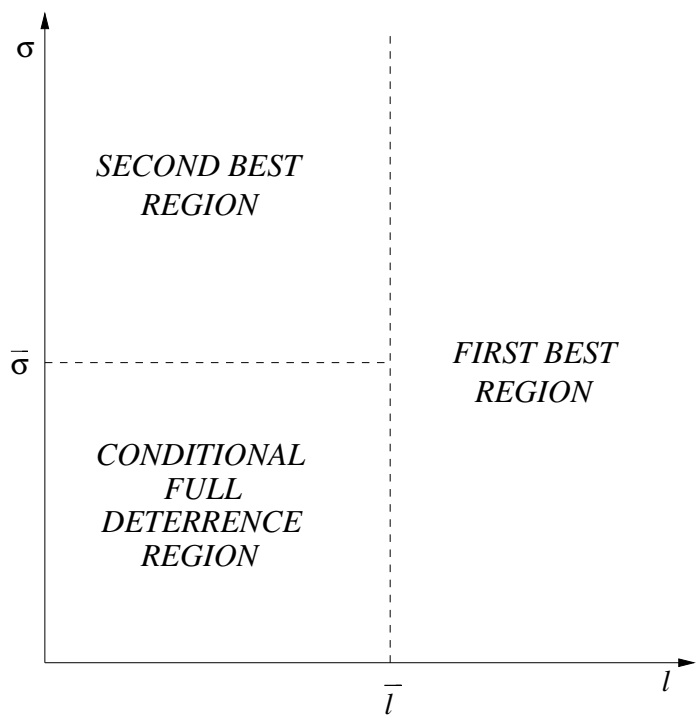

Fig. 2: Conditional Full Deterrence region.

Let us now consider the case of a dependent Judiciary. In particular we allow Nature to initially choose $l$ and $\sigma$, and give $P$ the power to select $J$, that is to change $\sigma$. We have thereby to consider the possibility that the lobby contributes $P$ also at this stage of the game to further their political ends. The timing is as follows:

\footnotetext{
${ }^{18}$ Note that the model remains a game of complete and perfect information in that $J$ and $P$ observe the outcomes of both the draws.
} 
(i) Nature chooses $l$ and $\sigma$ independently;

(ii) the lobbying group 1 formulates the contribution schedule $T^{I}(\sigma)$;

(iii) $P$ chooses either to keep $\sigma$ or to change it into $\hat{\sigma}$;

(iv) the lobbying group 1 formulates the contribution schedule $C(f)$;

(v) $J$ selects the level of control activity, determining $\hat{f}$, the lobby pays $T^{I}(\hat{\sigma})$ and $C(\hat{f})$;

(vi) if not traced, $T^{I}(\hat{\sigma})$ is received by $P$;

(vii) the lobbying group 1 formulates the contribution schedule $T^{I I}(q)$;

(viii) $P$ sets the policy $\hat{q}$, the lobby pays $T^{I I}(\hat{q})$;

(ix) if not traced, $T^{I I}(\hat{q})$ is received by $P$.

Note that in $V_{P}$ it results $T \equiv T^{I}+T^{I I}$. In the last stage of the game the first claim of Proposition 1 still applies and lobbying never occurs provided $l \theta_{1} \geq 1$. As to the solution of the game when $l<1 / \theta_{1}$, we prove the following:

Lemma 3. Let $l \theta_{1}<1$. In the SPE of the game:

i) $P$ chooses the pair $\left\{\hat{\sigma} \rightarrow \infty, q^{L}(\hat{f}=1)\right\}$;

ii) $J$ selects $\hat{f}=1$;

iii) the lobby pays $\left\{\widehat{C}(f)=0, \widehat{T}^{I}(\sigma)=0, \widehat{T}^{I I}(q)\right\}$ where:

$$
\widehat{T}^{I I}(q)=\frac{l}{1-l \theta_{1}}\left\{\sum_{k} \theta_{k}\left[U_{k}\left(\hat{q}_{k}^{*}\right)-U_{k}\left(\hat{q}_{k}^{L}(\hat{f}=1)\right)\right]\right\}
$$

Proof. - See Appendix E.

Intuitively, the lobby prefers $f=1$ to every other $f \in[0,1)$, since for any $f \leq l \theta_{1}, V_{1}=U\left(\hat{q}^{*}\right)$ obtains, while for $f>l \theta_{1}$ it holds $\frac{\partial V_{1}}{\partial f}>0$. For this scenario to emerge, it needs a sufficiently low level of integrity of the Judiciary and thus there exists an incentive for the special interest group to lobby $P$ at the first stage: since both the payoff functions of the lobby and of $P$ are decreasing in $C$, that is the contribution paid by the lobby to $J$, it proves optimal for them to jointly set it to zero, which turns possible in the case of a corruptible Judiciary only if its integrity is exactly zero. With an incorruptible Judiciary, it is easy to show that the lobby and $P$ share a common interest in changing $J$ and letting $\sigma \rightarrow \infty$; this result readily follows from observing that $\frac{\partial V_{P}}{\partial f}$ is positive if $T>0$ in correspondence of the optimal choice for $q$.

The equilibrium outcome under a dependent Judiciary is equivalent to that resulting from a society where no such an institutional entity exists; in both the cases indeed, the original finding of Grossman and Helpman (2001) obtains, where the weight $P$ grants the lobby within the choice of $\hat{q}^{L}$ is always as 
high as possible, i.e. $f=1$. Importantly, we may observe that, according to Corollary 2, the same conclusion results if $P$ is allowed to determine the level of efficiency of the Judiciary, rather than integrity. In particular, it is easy to show that there exists a (possibly zero) level of efficiency for every level of integrity of $J$, such that whenever $P$ implements it $J$ chooses $f=1$ and never claims a form of compensation to the lobby. Both the forms of dependence (organizational as much as hierarchical) appear thereby to be detrimental in the political equilibrium.

Regardless of how the Judiciary and the Politician are appointed, the likelihood of achieving the First Best solution never decreases. In fact, the presence of the Judiciary is redundant when $P$ is sufficiently welfare-interested and lobbying proves unfeasible, since any degree (and form) of institutional dependence will bring about the same result. Conversely, when $P$ is sufficiently concerned with the contributions offered by the lobby (i.e. $l<\bar{l}$ ), entrusting the political authority with power over $J$ rules out the possibility of achieving an equilibrium with (possibly partial) lobbying deterrence. A dependent Judiciary would indeed act as the perfect agent of the policy maker. Conversely, an independent Judiciary, even if corruptible, breaks the exclusive bargaining channel with the political authority, and thus weakens the lobby's incentives to engage in bribe-making, as the latter is more likely not to be able to create large rents. This in turn might reduce total corruption ${ }^{19}$.

\section{Conclusion}

This paper addresses several issues pertaining to the influence of a judicial authority on the presence of illegal contributions that groups of interest may choose to submit to a policy-setting authority with the aim of influencing the decision making upon the provision of public projects. An endogenous policy model is developed where the ability of a lobbying group to impinge on the determination of policies arises endogenously. In contrast to most of the related literature, here the tendered contributions do not systematically reach the political authority once this has solved its decision problem. Rather, the stage of lobbying is endogeneized in a framework where the transmission of monetary contributions - in the form of bribes - relies on the judicial authority's deterrence activity, whose level is unambiguously related to the probability of revealing corruption. The political authority will accept the contribution only if it is effectively secured with a given probability threshold. We find that the Judiciary plays a critical and heretofore unrecognized role in the shaping of public policies. As a result, the set of feasible alternatives against the status-quo may differ significantly in comparison to the setting where no judicial authority is considered. Whenever underdeterrence occurs in equilibrium,

\footnotetext{
${ }^{19}$ This insight is reminiscent of Rose-Ackerman (1978) argument that heightening the number of individuals who must be bribed in order to achieve the desired outcome may in fact be optimal.
} 
an increasing probability of reaching the political authority through the illegal contributions translates into an increasing lobbying power of the group of interest, with severe implications on the effective redistribution outcome.

As a modeling issue, the analysis presented herein investigates some relevant features which are commonly presumed to exert some degree of influence on the decision making process at the judicial level. In particular, two substantive dimensions are highlighted: the efficiency of Judiciary - which directly affects the choice of the level of the control activity to establish - and its integrity - which is likely to induce distortions in court behavior. It is shown that efficiency and integrity both entail several implications for the effectiveness of lobbying; in particular, we prove that, even when allowing for a corruptible Judiciary, the control activity may prevent the group of interest from lobbying in the political equilibrium, whenever the judicial authority acts in a sufficiently efficient environment. Provided a fraction of judges is held not easy to capture, improving efficiency of judicial review may serve as a measurable (controllable) instrument for accountability of this branch - since efficient judicial systems may countervail special interest groups' influence over prone-to-pressure courts. Still, for low levels of integrity a corrupt Judiciary represents an insurmountable impediment to the functioning of the institutional mechanism designed to curb corruption, however well-targeted and efficient, and no equilibrium with zero contributions is achievable.

Finally, the main findings are tested against different assumptions as to judicial independence. Empirical studies on the topic suggest that the institutional design of judicial authorities is likely to serve as a potential determinant of political corruption. Our theoretical approach provides one potential explanation for such evidence. In our framework, an independent, even corruptible, Judiciary is shown to be superior to a dependent one, insofar as deterrence equilibria are unfeasible under perfect (hierarchical as well as organizational) dependence. The independence of the judiciary is therefore crucial to its effectiveness, yet it is not sufficient, insofar as a fair judiciary must also be subject to mechanisms that hold it accountable for its institutional role. In a normative perspective, our results suggest that insulating judicial branches from political interference should configure an important issue of institution design. 


\section{Appendix}

A. Proof of Lemma 1 First note that from $\widehat{T}(f)=0$ when $f<l \theta_{1}$, it follows that $J$ optimizes over $f \in\left[l \theta_{1}, 1\right]$. The Lemma is proven in three steps:

1. Consider $\alpha_{I}$ such that, for $f \rightarrow l \theta_{1}^{+}, V_{J}\left(l \theta_{1}\right)>V_{J}(f)$, that is $S(f)+$ $\widehat{T}(f)>S\left(l \theta_{1}\right)$. The point $l \theta_{1}$ doesn't pose any discontinuity problem as the one-sided limits from above and below are finite and equal to $\widehat{T}\left(l \theta_{1}\right)=0$. Moreover, from $\widehat{T} \in C^{2}$, it follows that $\widehat{T}$ is $O\left(f-l \theta_{1}\right)$ in a neighborhood of $l \theta_{1}$. The threshold value $\alpha_{I}$ is accordingly identified through the following second-order Taylor expansion of $\widehat{T}(f)$ around $\left(l \theta_{1}\right)$ :

$$
\frac{(1-f)}{\alpha}+\left[\widehat{T}\left(l \theta_{i}\right)+\left(f_{i}-l \theta_{i}\right) \frac{\partial \widehat{T}}{\partial f}+\frac{\left(f-l \theta_{1}\right)^{2}}{2} \frac{\partial^{2} \widehat{T}}{\partial f^{2}}+R_{\widehat{T}}\right]>\frac{\left(1-l \theta_{1}\right)}{\alpha}
$$

which is equivalent to:

$$
\left(f-l \theta_{1}\right) \widehat{T}^{\prime}\left(l \theta_{1}\right)+\frac{\left(f-l \theta_{1}\right)^{2}}{2} \widehat{T}^{\prime \prime}\left(l \theta_{1}\right)+R_{\widehat{T}}>\frac{\left(f-l \theta_{1}\right)}{\alpha}
$$

which in turn holds for:

$$
\alpha>\frac{1}{\widehat{T}^{\prime}\left(l \theta_{1}\right)+\frac{\left(f-l \theta_{1}\right)}{2} \widehat{T}^{\prime \prime}\left(l \theta_{1}\right)+R_{\widehat{T}}}=\alpha_{I}
$$

2. Let $\hat{f}=\operatorname{argmax}\left\{V_{J}\right\}$ when $\alpha=\alpha_{I}$; if $\hat{f}>l \theta_{1}$, consider $\alpha_{I I}$ such that $S\left(l \theta_{1}\right)<S(\hat{f})+\widehat{T}(\hat{f})$. The previous expression translates into:

$$
\frac{\left(1-l \theta_{1}\right)}{\alpha}<\frac{(1-\hat{f})}{\alpha}+\frac{1}{\hat{f}-l \theta_{1}}\left\{l \sum_{k=1}^{2} \theta_{k}\left[U_{k}\left(q^{*}\right)-U_{k}\left(q^{L}\right)\right]\right\}
$$

which holds for:

$$
\alpha>\frac{\left(\hat{f}-l \theta_{1}\right)^{2}}{\left\{l \sum_{k=1}^{2} \theta_{k}\left[U_{k}\left(q^{*}\right)-U_{k}\left(q^{L}\right)\right]\right\}}=\alpha_{I I}
$$

3. Follow this iterative procedure until at $\alpha_{N}, \hat{f}=l \theta_{1}$ obtains. A finite $\alpha_{N}$ will exist as $\widehat{T}$ is bounded from below (i.e., $\widehat{T} \geq C$ on $\left[l \theta_{1}, 1\right], C$ is a constant). We will then have $\bar{\alpha}=\alpha_{N}$.

The first step ensures $V_{J}$ has a local maximum at $f=l \theta_{1}$. The second and third steps ensure this is also the global maximizer in $\left[l \theta_{1}, 1\right]$.

B. Proof of Lemma 2 Assume $\alpha \rightarrow \infty$. Consider the upper bound of the contribution paid by group 1 against $\hat{f}^{L}$ in this case. We can obtain it by making equation (13) hold with equality (with $\widehat{T}\left(\hat{f}^{*}\right)=0$ from Lemma 1 ):

$$
\left.\bar{C}\left(\hat{f}^{L}\right)=U\left(\hat{q}\left(\hat{f}^{L}\right)\right)\right)-U\left(\hat{q}\left(\hat{f}^{*}\right)\right)-\widehat{T}\left(\hat{f}^{L}\right)=\Delta U\left(\hat{q}\left(\hat{f}^{L}\right)\right)-\widehat{T}\left(\hat{f}^{L}\right)
$$


We can now substitute it in the objective function of $J$ to obtain:

$$
\bar{V}_{J}=-\frac{1}{1+\sigma} T(f)+\frac{\sigma}{1+\sigma}[\Delta U(\hat{q}(f))-\widehat{T}(f)]
$$

where $\bar{V}_{J}$ represents the maximum value $J$ could obtain by choosing $f$. Now we show that there exists $\bar{\sigma}$ such that for $\sigma<\bar{\sigma}$ the lobby could never guarantee that $J$ gains a payoff equal to $V_{J}\left(l \theta_{1}\right)$. From now on we consider - according to the discussion in the proof of Lemma 1 - only $f \in\left[l \theta_{1}, 1\right]$ and exploit the multi-step procedure as follows:

1. Consider $\sigma_{I}$ such that, for $f \rightarrow l \theta_{1}^{+}, \bar{V}_{J}\left(l \theta_{1}\right)>\bar{V}_{J}(f)$, that is $-T(f)+$ $\frac{\sigma}{1+\sigma} \Delta U(\hat{q}(f))<0$. We can rewrite this condition by adopting secondorder Taylor expansions of $\widehat{T}(f)$ and $U(\hat{q}(f))$ around $\left(l \theta_{1}\right)$ :

$$
\begin{array}{r}
-\left[\widehat{T}\left(l \theta_{i}\right)+\left(f_{i}-l \theta_{i}\right) \frac{\partial \widehat{T}}{\partial f}+\frac{\left(f-l \theta_{1}\right)^{2}}{2} \frac{\partial^{2} \widehat{T}}{\partial f^{2}}+R_{\widehat{T}}\right]+\frac{\sigma}{1+\sigma}\left[U\left(q\left(l \theta_{i}\right)\right)\right. \\
\left.+\left(f_{i}-l \theta_{i}\right) \frac{\partial U(\hat{q})}{\partial f}+\frac{\left(f-l \theta_{1}\right)^{2}}{2} \frac{\partial^{2} U(\hat{q})}{\partial f^{2}}+R_{U}-U\left(q\left(l \theta_{i}\right)\right)\right]<0
\end{array}
$$

which is equivalent to:

$$
\begin{array}{r}
-\left[\left(f_{i}-l \theta_{i}\right) \frac{\partial \widehat{T}}{\partial f}+\frac{\left(f-l \theta_{1}\right)^{2}}{2} \frac{\partial^{2} \widehat{T}}{\partial f^{2}}+R_{\widehat{T}}\right] \\
+\frac{\sigma}{1+\sigma}\left[\left(f_{i}-l \theta_{i}\right) \frac{\partial U(\hat{q})}{\partial f}+\frac{\left(f-l \theta_{1}\right)^{2}}{2} \frac{\partial^{2} U(\hat{q})}{\partial f^{2}}+R_{U}\right]<0
\end{array}
$$

which in turn holds for:

$$
\sigma<\frac{\left(f_{i}-l \theta_{i}\right) \frac{\partial \widehat{T}}{\partial f}+\frac{\left(f-l \theta_{1}\right)^{2}}{2} \frac{\partial^{2} \widehat{T}}{\partial f^{2}}+R_{\widehat{T}}}{\left(f_{i}-l \theta_{i}\right)\left(\frac{\partial U(\hat{q})}{\partial f}-\frac{\partial \widehat{T}}{\partial f}\right)+\frac{\left(f-l \theta_{1}\right)^{2}}{2}\left(\frac{\partial^{2} U(\hat{q})}{\partial f^{2}}-\frac{\partial \widehat{T}}{\partial f}\right)+\left(R_{U}-R_{\widehat{T}}\right)}=\sigma_{I}
$$

2. Let $\hat{f}=\operatorname{argmax}\left\{V_{J}\right\}$ when $\sigma=\sigma_{I}$; if $\hat{f}>l \theta_{1}$, consider $\sigma_{I I}$ such that $-T(\hat{f})+\frac{\sigma}{1+\sigma} \Delta U(\hat{q}(\hat{f}))<0$ which holds for:

$$
\sigma<\frac{T(\hat{f})}{\Delta U(\hat{q}(\hat{f}))-\widehat{T}(\hat{f})}=\sigma_{I I}
$$

3. Follow this iterative procedure until at $\sigma_{N}, \hat{f}=l \theta_{1}$ obtains. A finite $\sigma_{N}$ will exist since, for $\sigma=0, \mathrm{~J}$ chooses $\hat{f}^{L}=l \theta_{1}$ since $T\left(l \theta_{1}\right)=0$ and $T(f)>0 \forall f>l \theta_{1}$, while, for $\sigma \rightarrow \infty$, J chooses $\hat{f}^{L}>l \theta_{1}$ since $\Delta U(\hat{q}(f))-\widehat{T}(f)>0$ and $T(f)$ is bounded. We will then have $\bar{\sigma}=\sigma_{N}$. 
The first step ensures $\bar{V}_{J}$ has a local maximum at $f=l \theta_{1}$. The second and third steps ensure this is also the global maximizer in $\left[l \theta_{1}, 1\right]$.

C. Proof of Corollary 1 It follows directly by Lemma 1 and Lemma 2. Note that if $\alpha$ is finite and positive, it is easier for the lobby to respect the (IC) of $J$; in particular we can now rewrite the condition $\bar{V}_{J}(f)-\bar{V}_{J}\left(l \theta_{1}\right)=0$ for $f>l \theta_{1}$ as:

$$
T(f)-\sigma[\Delta U(\hat{q}(f))-\widehat{T}(f)]+\Delta S(f)=0
$$

where $\Delta S(f)$ is negative and decreasing in $\alpha$; so we can obtain the mapping from $\alpha$ to $\sigma$ of the values that respect this expression.

D. Proof of Corollary 2 The proof for $\sigma=0$ is similar to that of Lemma 1 . However in this case we need to show that $f=1$ maximizes $V_{J}$ in $[0,1]$. Define $\alpha_{I}=1 / T^{\prime}(f=1)$. If $\alpha<\alpha_{I}, T(1)$ is a local maximum for $V_{J}$. Now, consider $\hat{f} \equiv \operatorname{argmax}\left\{V_{J}\right\} \in[0,1]$; if $\hat{f}<1$ define $\alpha_{I I}=\frac{1-\hat{f}}{T(\hat{f})-T(1)}<\alpha_{I}$. Iterating, we can find $\alpha_{N}=\underline{\alpha}(0)$ such that $f=1 \equiv \operatorname{argmax}\left\{V_{J}\right\} \in[0,1]$. Lastly, if for $\alpha=\underline{\alpha}(0) f=1 \equiv \operatorname{argmax}\left\{V_{J}\right\}$, this is true $\forall \alpha<\underline{\alpha}(0)$ since $V_{J}$ is decreasing in $\alpha \in[0,1)$.

Now suppose a generic $\sigma>0$. We can find $\underline{\alpha}(\sigma)$ with the same procedure as before; however, denoting with $V_{J}^{C}=V_{J}^{N C}+\sigma C$ the payoffs of a corruptible and non-corruptible $J$ respectively, we note that now it is easy to respect all the sequence of conditions since $\frac{\partial C}{\partial f}$ is positive (and the amount that the interest group is willing to pay to lobby $J$ is maximum for $f=1$ ). Starting from $\alpha_{I}=1 /\left(T^{\prime}(f=1)-\sigma C^{\prime}(f=1)\right)$, we can obtain another sequence that converges to $\underline{\alpha}(\sigma)$. Since every term of the sequence is increasing in $\sigma$-note that every $\alpha_{n}$ after $\alpha_{I}$ looks like $\frac{1-\hat{f}}{T(\hat{f})-T(1)-\sigma(C(1)-C(\hat{f}))}$, it follows that $\underline{\alpha}(\sigma)$ is increasing in $\sigma$.

E. Proof of Lemma 3: We solve again the game by backward induction:

1. In the third stage, given $\hat{f}$ - that is, the level of control chosen in the second stage -, we obtain $q(\hat{f})$ and $T^{I I}(q(\hat{f}))$ as before;

2. In the second stage, given $\hat{\sigma}, \hat{f}$ and $C(\hat{f})$ are determined;

3. As to the first stage, we begin determining the optimal solution for the lobby. We previously showed that $\forall f \leq l \theta_{1} V_{1}=U\left(q^{*}\right)$ while, if $f>l \theta_{1}$, from $\frac{\partial q}{\partial f}>0$ and $\frac{\partial V_{1}}{\partial q}>0$, it follows that $\frac{\partial V_{1}}{\partial f}>0$ so that the lobby strictly prefers $f=1$ to any $f \in[0,1)$. Also, we can note that both $V_{1}$ and $V_{P}$ are decreasing in $C$ at the optimum. In particular, $V_{P}^{L}=$ $l \sum_{i} \theta_{i} U_{i}\left(q^{*}\right)-l \theta_{2} C(\hat{f})$ and $V_{1}^{L}=U(\hat{q})-T(\hat{q})-C(\hat{f})$. From this it follows directly that in the NE of the subgame it is jointly optimal for $P$ and the lobby to set $f=1$ and $C=0$. In particular, $P$ chooses $\sigma \rightarrow \infty$ since this is equivalent to choosing $f=1$ with certainty and determining 
$\widehat{C}=0$. To show this, we consider the optimal solution for the problem of $J$. From section $4, \hat{f}$ maximizes $-(S+T)+\sigma C$ subject to the constraint $\frac{\partial U}{\partial f}-\frac{\partial T}{\partial f}-\frac{\partial C}{\partial f}=0$. Then $\hat{f}$ satisfies:

$$
-\frac{\partial S}{\partial f}-\frac{\partial T}{\partial f}+\sigma\left[\frac{\partial U}{\partial f}-\frac{\partial T}{\partial f}\right]=0
$$

or:

$$
-\frac{1}{\sigma}\left[\frac{\partial S}{\partial f}-\frac{\partial T}{\partial f}\right]+\frac{\partial U}{\partial f}-\frac{\partial T}{\partial f}=0
$$

so that for $\sigma \rightarrow \infty$ the solution to this problem coincides with the optimal choice for the lobby, which was showed to be equal to $f=1$. Lastly, from (12), we can observe that $C \rightarrow 0$ as $\sigma \rightarrow \infty$, since the term in brackets is bounded from above.

Accordingly, the whole game reduces to a single stage game where $P$ chooses the pair $\left(\infty, q^{L}(\hat{f}=1)\right)$ and the lobby pays $T^{I}+T^{I I}$, so that in equilibrium it must be:

$$
\widehat{T}^{I}+\widehat{T}^{I I}=\frac{1}{1-l \theta_{1}}\left\{l \sum_{k} \theta_{k}\left[U_{k}\left(q^{*}\right)-U_{k}\left(q^{L}(\hat{f}=1)\right)\right]\right\}
$$

However, the only time-consistent pair of $T^{I}$ and $T^{I I}$ is given by $T^{I}=0$ and $T^{I I}=\frac{l}{1-l \theta_{1}}\left\{\sum_{k} \theta_{k}\left[U_{k}\left(q^{*}\right)-U_{k}\left(q^{L}(\hat{f}=1)\right)\right]\right\}$, since the lobby pays $T^{I}$ prior to the decision over the policy $q^{L}$. 


\section{References}

[1] Aaken, van A., Feld, L.P., Voigt, S., 2008. Power over Prosecutors Corrupts Politicians: Cross Country Evidence Using a New Indicator. CESifo working paper No. 2245.

[2] Ades, A., Di Tella, R., 1997. The New Economics of Corruption: A Survey and some New Results. Political Studies, 45, pp. 496-515.

[3] Aidt, T.S., 2003. Economic Analysis of Corruption: A Survey. Economic Journal, 113, pp. 632-652.

[4] Alesina, A., Rosenthal, H., 1996. A Theory of Divided Government. Econometrica, 64, pp. 1311-1341.

[5] Becker G.S., Stigler G.J., 1974. Law enforcement, Malfeasance, and the Compensation of Enforcers. Journal of Legal Studies, 3, pp. 1-18.

[6] Bernholz, P., 1973. Logrolling, Arrow Paradox and Cyclical Majorities. Public Choice, 15, pp. 87-95.

[7] Bond, P., 2009. Contracting in the Presence of Judicial Agency. The B.E. Journal of Theoretical Economics, 9, Article 36.

[8] Boudreaux, D.J., Pritchard, A.C., 1994. Reassessing the Role of the Independent Judiciary in Enforcing Interest-Group Bargains. Constitutional Political Economy, 5, pp. 1-21.

[9] Buchanan, J.M., Tullock, G., 1962. The Calculus of Consent: Logical Foundations of Constitutional Democracy. University of Michigan Press.

[10] Caselli, F., Morelli, M., 2004. Bad Politicians. Journal of Public Economics, 88, pp. 759-782.

[11] Coate, S., Morris, S., 1999. Policy Persistence. American Economic Review, 89, pp. 1327-1336.

[12] Collins, P.M., 2008. Friends of the Supreme Court: Interest Groups and Judicial Decision Making. Oxford University Press.

[13] Dakolias, M., 1999. Court Performance Around the World: A Comparative Perspective. Yale Human Rights and Development Law Journal, 2, pp. $87-142$.

[14] Dal Bó, E., Dal Bó, P., Di Tella, R., 2006. 'Plata o Plomo?': Bribe and Punishment in a Theory of Political Influence. American Political Science Review, 100, pp. 1-13.

[15] Dixit, A., Grossman, G.M., Helpman, E., 1997. Common Agency and Coordination: General Theory and Application to Government Policy Making. Journal of Political Economy, 105, pp. 752-769. 
[16] Feld, L.P., Voigt, S., 2003. Economic Growth and Judicial Independence: Cross Country Evidence Using a New Set of Indicators. European Journal of Political Economy, 19, pp. 497-527.

[17] Feld, L.P., Voigt, S.. 2004. Making Judges Independent. Some Proposals Regarding the Judiciary. CESifo working paper No. 1260.

[18] Glaeser, E.L., Shleifer, A., 2002. Legal Origins. Quarterly Journal of Economics, 117, pp. 1193-1229.

[19] Grossman, G.M., Helpman, E., 1994. Protection for Sale. American Economic Review, 84, pp. 833-850.

[20] Grossman, G.M., Helpman, E., 2001. Special Interest Politics. Cambridge MA., MIT Press.

[21] Hanssen, A.F., 2004. Is There a Politically Optimal Level of Judicial Independence?. American Economic Review, 94, pp. 712-729.

[22] Harstad, B., Svensson, J., 2006. Bribes, Lobbying and Development. CEPR discussion paper No. 5759.

[23] Hellman, J.S., Jones, G., Kaufman, D., 2000. Seize the State, Seize the Day: State Capture, Corruption, and Influence in Transition. World Bank Policy Research Paper No. 2444.

[24] Hillman, A.L., 1982. Declining Industries and Political-Support Protectionist Motives. American Economic Review, 72, pp. 1180-1187.

[25] Hillman, A.L., 1989. The Political Economy of Protection. Chur: Harwood, 1989.

[26] Hillman, A.L., Katz, E., 1987. Hierarchical Structure and the Social Cost of Bribes and Transfers. Journal of Public Economics, 34, pp. 129-142.

[27] Hoeflich, M.H., 1984. Regulation of Judicial Misconduct from Late Antiquity to the Early Middle Ages. Law and History Review, 2, pp. 79-104.

[28] Immordino, G., Pagano, M., forthcoming. Legal Standards, Enforcement and Corruption. Journal of the European Economic Association.

[29] Jain, A.K., 2001. Corruption: A review. Journal of Economic Surveys, 15, pp. $71-121$.

[30] La Porta, R., Lopez-de-Silanes, F., Pop-Eleches, C., Shleifer, A., 2004. Judicial Checks and Balances. Journal of Political Economy, 112, pp. 445-470.

[31] Laffont, J.J., 2000. Incentives and Political Economy. Oxford: Oxford University Press. 
[32] Landes, W.M., Posner, R.A., 1975. The Independent Judiciary in an Interest-Group Perspective. Journal of LawEEEconomics, 18, pp. 875-901.

[33] Maskin, E., Tirole, J., 2004. The Politician and the Judge: Accountability in Government. American Economic Review, Vol. 94 pp. 1034-1054.

[34] Mauro, P., 1995. Corruption and Growth. Quarterly Journal of Economics, 110, pp. 681-712.

[35] Mazza, I., van Winden, F., 2008. An Endogenous Policy Model of Hierarchical Government. European Economic Review, 52, pp. 133-149.

[36] McMillan, J., Zoido, P., 2004. How to Subvert Democracy: Montesinos in Peru. Journal of Economic Perspectives, 18, pp. 69-92.

[37] Olson, M., 1965. The Logic of Collective Action: Public Goods and the Theory of Groups. Cambridge: Harvard University Press.

[38] Persson, T., Tabellini, G., 2003. The Economic Effects of Constitutions: What Do the Data Say? Cambridge: MIT Press.

[39] Persson, T., Roland, G., Tabellini, G., 1997. Separation of Powers and Political Accountability. The Quarterly Journal of Economics, 112, pp. 1163-1202.

[40] Peters, M., 2003. Negotiation and Take-it-or-leave-it in Common Agency. Journal of Economic Theory, 111, pp. 88-109.

[41] Polinsky, A.M., Shavell, S., 2001. Corruption and Optimal Law Enforcement. Journal of Public Economics, 81, pp. 1-24.

[42] Posner, R.A., 1994. What Do Judges and Justices Maximize? (The Same Thing Everybody Else Does). Supreme Court Economic Review, 3, pp. $1-41$.

[43] Posner, R.A., 1995. Overcoming Law. Cambridge MA.: Harvard University Press.

[44] Priks, M., 2007. Judiciaries in Corrups Societes. CESifo working paper No. 2008.

[45] Rose-Ackerman, S., 1978. Corruption: A Study in Political Economy. New York: Academic Press.

[46] Rubin, P.H., Curran, C., Curran, J.F., 2001. Litigation Versus Legislation: Forum Shopping by Rent Seekers. Public Choice, 107, pp. 295-310.

[47] Stigler, G.J., 1971. The Theory of Economic Regulation. Bell Journal of Economics, 2, pp. 359-365. 